\title{
Present Situation and Countermeasures of Humanistic Education in Physical Education in Colleges and Universities of China
}

\author{
Wanwen Su, Xianhui Liu \\ Minjiang University, Fuzhou, 350121, China
}

Keywords: physical education in colleges and universities; humanistic education; present situation; countermeasures

\begin{abstract}
Humanistic education refers to a various conscious and practical activities which aim at promoting the improvement of human nature, shaping ideal personality and realizing individual and social value. Humanity education is the essence of humanistic education, and the cultivation of humanistic spirit is the core of humanistic education. Humanistic education in physical education of colleges and universities is propitious to make students achieve improvement in physical condition and at the same time promote their ideological and moral qualities. Thus, it is essential to stimulate the cultivation of college students' comprehensive quality. This paper summarizes the present situation of humanistic education in colleges and universities and countermeasures to strengthen it.
\end{abstract}

\section{Introduction}

With the development of society and the improvement of economic level, the material living standard of people has been greatly improved, but the physical quality of most people is not as good as before, especially college students whose physical fitness gradually decline in their development stage of youth. Physical Education is the key to improve the physical quality of college students and Humanistic Education is an important measure to train college students to set up people-oriented thoughts and improve their ideological quality. At present, domestic education usually pays more attention to the cultivation of professional knowledge and skills, resulting in students' low level of ideological and moral quality, therefore there are many students with distorted outlook on life and values. In college and university education, because of the need for the ability of independence and autonomy, some college students not only lack professional knowledge and skills, but also have extremely low level of ideological and moral quality. Physical Education set up relatively positive courses for students, so Humanistic Education in Physical Education in colleges and universities can better carry out the spirit of Humanistic Education, then cultivate the comprehensive quality of college students and improve their values, outlook on life and world.

\section{Humanistic Education is Important in Physical Education in Colleges and Universities}

Humanistic Education for college students is the key to ensure their mastery of professional knowledge and skills, improve their comprehensive quality, and establish correct values, outlook on life and world outlook. Through the cultivation of college students' humanistic quality, students will be capable of making greater contribution to the society. In addition, it also can increase their enthusiasm to carry out Humanistic Education through Physical Education, achieve better popularization of Humanistic Education, therefore, Humanistic Education in Physical Education in colleges and universities is of great importance to the cultivation and development of students.

With the continuous development and progress of human society, various sports cultural systems emerge gradually, which makes the spiritual connotation very different. Under the background of new era, new concepts have been put forward, and the harmonious development of people has become the common goal of promoting the harmonious development of society. Olympic Culture has gradually become the mainstream of sports culture in the world, and the concept of national fitness has spread wide in China. Therefore, it is more and more important to pay more attention to the cultivation of humanistic spirit while improving the physical quality of individuals. Thus, it is 
the key of modern social education to integrate Humanistic Education into Physical Education and strengthen Humanistic Education of college students so as to improve their humanistic literacy.

At present, there is a general phenomenon that talents transferred to society who have received higher education in China have a relatively good grasp of their major knowledge, while they have little understanding of professional knowledge of other areas as well as Moral accomplishment. As a result of the neglect of Humanistic Education in colleges and universities, students have formed a lot of bad behaviors and ideas, as well as a distorted outlook on life and values, for example, the existence of bad atmosphere among students, a lack of self-restraint in speech and behavior, and relatively low ideology and morality. In view of the above problems, paying attention to Humanistic Education in college education will certainly restrain the formation of unhealthy atmosphere, improve the personality of college students, and enhance their comprehensive literacy. Then when stepping out of college, they will be able to face the society with a more perfect attitude. Humanistic Education in Physical Education in colleges and universities will not only promote the individual, but also stimulate the realization of personal career, and enhance the overall development of society.

In the development of economic globalization, the widespread application of network science and technology, and the spread of some dross ideas among people, such as individualism, hedonism, money worship and selfishness, seriously affect the ideological and moral quality of the whole nation. Especially for college students who just begin to approach the society step by step and lack experience in life, they are easily shaken by these dross thoughts, have misinterpretation, gradually form a bad atmosphere and do not want to be enterprising. In addition, since college students are the main force of social development and progress in the future, it is also a threatening to the development of society. Therefore, Humanistic Education must be carried out to help college students establish a correct outlook on life and values, cultivate good accomplishment and improve their overall quality.

In the present era of rapid development and continuous innovation, people must follow the pace of the times to adapt to the new relations of production, productivity and lifestyle. The core of Humanistic Education is intellectual education, which people must carry out to adapt to society. In the same way, it is more important for college students, so the contents of Physical Education can be enriched by applying Humanistic Education to Physical Education which not only can improve the physical quality of college students, but also cultivate their ideological and moral quality and strong will. Values of humanistic spirit and Humanistic Education are embodied in the affirmation of the status of Physical Education in colleges and universities that is also the full affirmation of its important role. Therefore, Physical Education in colleges and universities has a strong ideological foundation to ensure the sustainable development of efficient Physical Education.

\section{Present Situation of Humanistic Education in Efficient Physical Education}

All along, in the general concept of people, Physical Education is to strengthen physical fitness and enhance physical quality. Because of this kind of ideological consciousness, we usually only take the improvement of physical fitness as the core content of Physical Education. As a result, Humanistic Education fail to attract importance in Physical Education, which has seriously affected the reform and development of Physical Education in China.

With the increase of college graduates year by year, the pressure of employment is also increasing. Under this background, colleges and universities pay more attention to the cultivation of professional knowledge and skills but neglect physical training. In the current university study, only freshmen and sophomores will have Physical Education courses, but there will be no more in the future, which results in a serious absence of Physical Education. In addition, in the Physical Education of colleges and universities, more attention is paid to the improvement of physical quality but little to the cultivation of humanistic quality, which leads to a weak consciousness of humanistic accomplishment. 


\section{Low Humanistic Quality of Physical Education Teachers}

The humanistic quality of Physical Education teachers in colleges and universities has a direct impact on the Humanistic Education effect. Because many Physical Education teachers are graduates with Physical Education major, there is not efficient Humanistic Education in their learning process. Besides, most of them are sports specialty students and lack knowledge, which leads to their low level of humanistic quality and increase the difficulty to carry on humanities education.

\section{Countermeasures of Constructing Humanistic Education System}

The purpose of university education is to train talents with all-round development to adapt to the development of society. Therefore, in the Physical Education of universities, we must also pay attention to all-round cultivation. It is proposed to not only pay attention to students' improvement of sports quality, but also perfect their personality and enhance their comprehensive quality. Therefore, Physical Education is the most important part in the cultivation of talents.

During Physical Education in university, it is necessary to strengthen the propaganda of Humanistic Education so that both students and teachers can realize that Physical Education is an important measure of Humanistic Education. Because of the current Physical Education, people universally take it as a measure to strengthen physical fitness but fail to realize the importance of students' healthy personality, healthy psychology and positive attitude to life. Therefore, it is a necessity for us to establish the guiding ideology, create the environment of Humanistic Education, and change Humanistic Education to be the focus of education. The construction of humanistic teaching environment should be combined with students' demand for entertainment in Physical Education, adhere to the guiding ideology of physical happiness and health, and create a good teaching atmosphere. Due to examination-oriented education, Physical Education often pays attention to the test of students' sports skills and abilities, which destroys the good phenomenon of Physical Education. Therefore, we must maintain a relaxed and pleasant atmosphere, promote students' relaxation, and coordinate their development of body and mind.

In the present situation of Physical Education in China, the rationality of curriculum design and the soundness of curriculum scheme are common problems. Curriculum plan is the document that plays a guiding role in the course establishment and teaching, but the curriculum scheme in Physical Education cannot be applied to the teaching in different regions and colleges. In addition, the single infrastructure of Physical Education curriculum also weakens the enthusiasm of students, which is not conducive to improving their humanistic accomplishment. In view of the above problems, the curriculum of Physical Education in colleges and universities must organize pertinent teaching and training according to students' different interests and hobbies, and at the same time, perfect the establishment of Physical Education infrastructure according to the needs of students.

First, in the process of realizing and transcending the self, Physical Education are playing a great role. In the course of physical exercise, we are often our own opponent. So, in this process, we can achieve ourselves and transcend ourselves. After college students enter the society, they need to continue to surpass themselves in the process of development. In Humanistic Education of Physical Education, only students learn more actively, can they improve their humanistic quality. Therefore, we must pay attention to their cultivation of a positive and healthy mentality.

Teachers' humanistic quality directly affects their educational level. With the encouragement and influence of teachers' cultural quality, work attitude, language art, ideological quality and other factors, students' humanistic quality will also be promoted or reduced. Of course, Physical Education teachers' cultural quality also plays the same role. Their accomplishment is an important factor to promote the construction of Humanistic Education system in Physical Education, which is directly related to the humanistic cultivation of students. University or college is a transitional stage for students to enter the society. In this stage, students' values, outlook on life and world are gradually formed, so teachers' words and deeds directly affect their ideology. Therefore, it is necessary to strengthen teachers' cultural quality, perfect the system of selecting and training, set up 
high-quality teachers, and guarantee students to set up the correct values. During the cultivation of teachers' cultural quality, a corresponding reward mechanism can be set up to improve teachers' enthusiasm for learning.

In the process of constructing the system of Humanistic Education in Physical Education, we can strengthen Humanistic Education through various activities, such as sports cultural activities and sports competitions. Through different channels, Humanistic Education activities in the campus of colleges and universities can create a good educational atmosphere and promote the all-round development of students through all aspects of Humanistic Education, such as morality, intelligence, sports, aesthetics and labour.

\section{Conclusion}

Strengthening the cultivation of Humanistic Education in Physical Education in colleges and universities is the development trend of current education. At present, there are still many problems in Humanistic Education, so we must find appropriate countermeasures as soon as possible in order to improve the Humanistic Education system, improve humanistic quality of college students and promote the development of education.

\section{References}

[1] Yao Jianming. Present Situation and Countermeasures of Humanistic Education in Physical Education in Colleges and Universities in China [J]. Contemporary Sports Technology, 2014, 4(03):86-87.

[2] Wang Yahui. Research on Current Situation and Countermeasures of Physical Education in Colleges and Universities [J]. Youth Sports, 2015(07):64-65+93.

[3] Shu Jun. Discussion on the Countermeasures of Constructing Humanistic Education System of Physical Education in Colleges and Universities [J]. Journal of Nanchang College of Education, 2013, 28(12):176-177.

[4] Deng Xiaolan. A Study on the Predicament and Countermeasures of Humanistic Education in Physical Education in Colleges and Universities [J]. China Adult Education, 2012(10):144-145.

[5] Gao Weizhe, Zhao Zhenbo. Reasons and Countermeasures for the Shortage of Humanistic Quality of Physical Education Majors in Colleges and Universities [J]. China Adult Education, 2007(09):76-77.

[6] Han Chunli. Present Situation and Reform Countermeasures of Higher Physical Education of Major Students in China [J]. Journal of Wuhan Institute of Physical Education, 2005(07):92-95. 